\title{
Origin of banded structure and coal lithotype cycles in Kargali coal seam of East Bokaro sub-basin, Jharkhand, India: Environmental implications
}

\author{
Ram Chandra Tewari ${ }^{1, *}$ and Zahid A Khan ${ }^{2}$ \\ ${ }^{1}$ Department of Geology, Sri J.N.P.G. College, Lucknow 226 001, India. \\ 2504 W.R. Apartments, 5 J.C. Bose Marg, Lucknow 226 001, India. \\ ${ }^{*}$ Corresponding author. e-mail: ram_tewari@yahoo.com
}

The Kargali seam of Early Permian Barakar cyclothems of East Bokaro sub-basin of Jharkhand, India is $12-30 \mathrm{~m}$ thick, splits into two parts, and extends throughout the length of the basin. It is made up of interbedded sequences and variable proportions of Vitrain, Clarain, Durain and Fusain. Application of embedded Markov chain model rejects the phenomenon of randomness in the repetition of coal lithotypes. The preferential upward transition path for coal lithotypes that can be derived for the Kargali top coal seam is: Vitrain $\rightarrow$ Clarain $\rightarrow$ Durain $\leftrightarrow$ Fusain $\rightarrow$ Vitrain, and for the Kargali bottom coal seam is: Clarain $\leftrightarrow$ Vitrain $\rightarrow$ Fusain $\rightarrow$ Durain $\rightarrow$ Clarain. By and large, the cyclic repetition of coal lithotypes is similar in the Kargali bottom and top seams. Among the noteworthy features are two-way transitions between Durain and Fusian in Kargali top and between Clarain and Vitrain in the case of Kargali bottom coal seam. Entropy analysis corroborates Markov chain and indicates the presence of type A-4 asymmetrical cycles of coal lithotypes.

It is suggested that the banded structure of a coal seam is not a random feature and follows a definite cyclic pattern in the occurrence of coal lithotypes in vertical order and is similar to that described in Australian and European coal seams. Asymmetrical cyclic sequences are a normal, rather than an unusual condition, within coal seams. It is visualized that a gradual decline of toxic environment and ground water level resulted in the coal lithotype cycles in the Kargali seam of East Bokaro sub-basin. The close interbedding of Vitrain and Clarain is suggestive of seasonal fluctuation in anaerobic and aerobic conditions during peat formation.

\section{Introduction}

The Early Permian Barakar Formation of Gondwana Supergroup of peninsular India is the chief repository of sub-bituminous and bituminous coal. It is widely exposed in most of the Gondwana basins of eastern and central India. The lithofacies and sedimentary characters of Barakar coal measures are studied locally in small sub-basins and regionally across the Gondwana Master Basins in fairly good detail (Casshyap 1979; Casshyap and Tewari 1984, 1988; Veevers and Tewari 1995; Tewari 2005;
Tewari et al. 2012). In addition, attempts are made to analyze and interpret cyclic characters, and interrelationships of stratigraphic and lithologic variables using Markov chain, entropy function, cluster analysis, principal component analysis, and factor analysis (Khan and Casshyap 1981; Casshyap and Tewari 1984; Casshyap et al. 1988; Tewari 1997, 2008; Hota and Maejima 2004; Tewari et al. 2009; Khan and Tewari 2010, 2011, 2012, 2013). The Barakar sediments are composed of finingupward cycles (cyclothems) of coarse to medium grained channel to sheet-like and multi-storey

Keywords. Coal lithotypes; Permian; embedded Markov chain; entropy; Gondwana. 
sandstone, occasionally pebbly sandstone and conglomerate, thin lens-like and thick sheet-like shale, and coal seams, and represent braided and meandering stream deposits. The enclosed coal seams are thin (up to $3 \mathrm{~m}$ ) as well as thick. The thicker seams are sheet-like $(20-30 \mathrm{~m})$, extend for several $\mathrm{km}$ along the strike, and often show splitting. Attempts are made to analyze and interpret the chemical characteristics, macerals, coal maturation, and petrography of Permian Gondwana coal (Stach et al. 1982; Mishra et al. 1990; Singh and Dwivedi 1994; Sen 1999, 2010; Singh and Shukla 2004; Singh and Singh 2004; Singh et al. 2012). In spite of many good studies of coal bearing successions, little or no attempt has been made to analyze and interpret vertical relationship of coal lithotypes.

The present study is the first attempt to quantitatively evaluate the vertical relationship between coal lithotypes in Kargali (top and bottom) coal seam, East Bokaro sub-basin by using Markov chain analysis and Entropy function. The results may have significant implications with respect to the origin of banded structure in coal lithotypes.

\section{Geological setting and sedimentary characters}

The Gondwana Master Basins of peninsular India occupying present day river valleys occur either as continuous elongated outcrops or separate outliers (coal fields) forming a linear belt. Structurally, these basins are graben and half-graben bounded by high angle normal faults. Reviewing the earlier opinions on peninsular India Gondwana basin configuration, Tewari and Maejima (2010) suggested Early Permian and late Jurassic-Early Cretaceous rifting, respectively for the initiation and termination of Gondwana basins.

The East Bokaro sub-basin is an important coal producing area of east-west oriented KoelDamodar valley Gondwana basins of eastern India (figure 1). It occurs as a graben bounded by normal east-west faults along the northern and southern margins and stretches for about $25 \times 7 \mathrm{~km}$ in the Hazaribagh district of Jharkhand (formerly Bihar). Table 1 lists the stratigraphy and sedimentary characters of Gondwana rocks of East Bokaro sub-basin. The Gondwana stratigraphy comprises

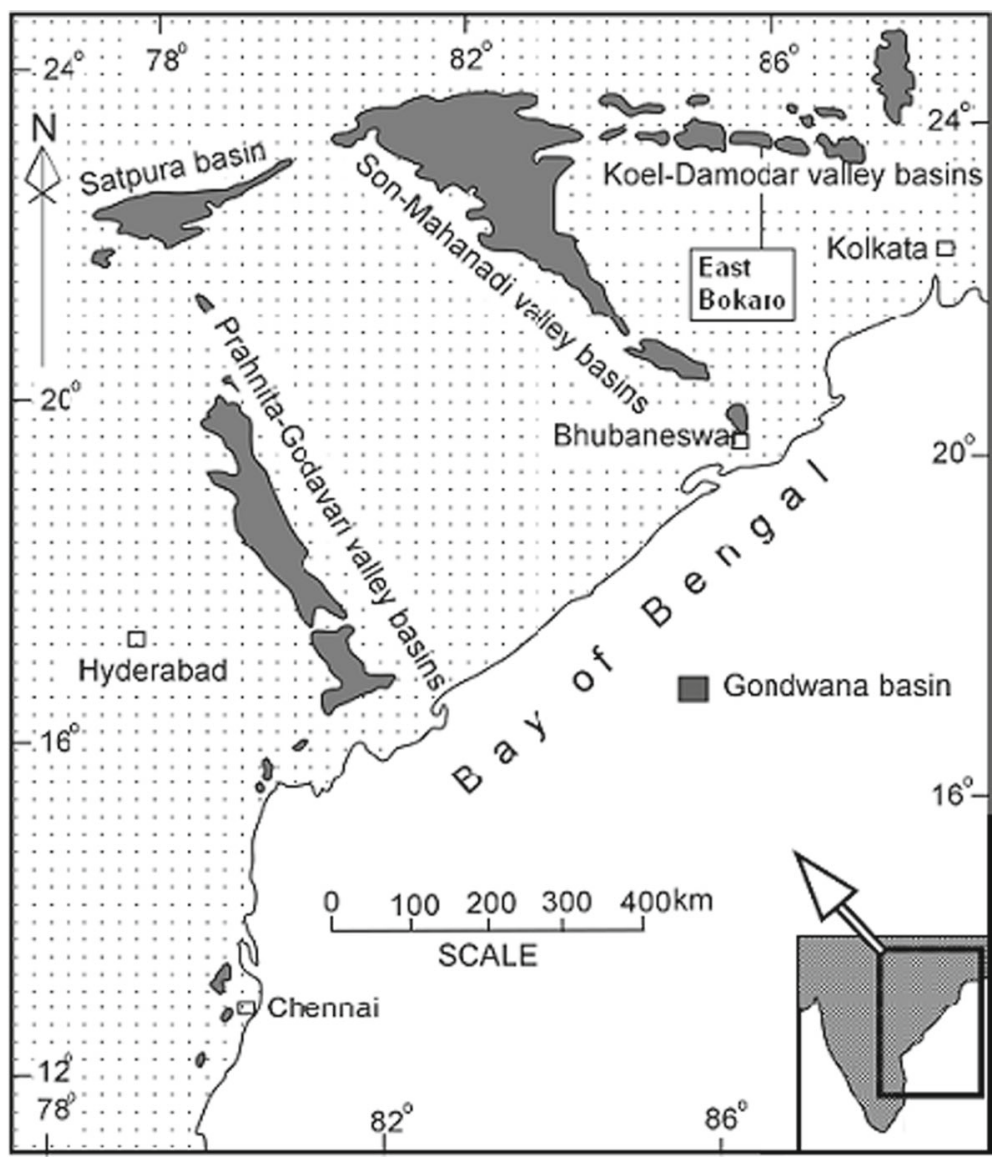

Figure 1. Location map of Gondwana master basins of eastern-central India showing East Bokaro area. 
Talchir, Karharbari, Barakar, and Barren Measures, respectively in vertical order (figure 2). In the East Bokaro sub-basin, the Early Permian Barakar Formation is about $800 \mathrm{~m}$ thick and contains five workable coal seams (figure 3). The coal bearing fluvial Barakar Formation of peninsular India Gondwana basins is extensively studied for surface and sub-surface lithofacies, sedimentary characters, and depositional facies models (Casshyap and Tewari 1984, 1988; Tewari 2005; Tewari et al. 2012). Significant contributions of Barakar Formation of East Bokaro sub-basin are those of Khan and Casshyap (1981, 1982) and
Casshyap and Khan (1982). These coal measures have been interpreted as meandering stream depositional model with northwesterly paleoslopes and characteristic fining upward fluvial cycles (Casshyap and Khan 1982; Casshyap and Tewari 1984). The Kargali seam $(12-30 \mathrm{~m})$ extends throughout the length of the basin and splits into two parts named as Kargali Top and Kargali Bottom, separated by lens-shaped mediumgrained sandstone of $20-30 \mathrm{~m}$ thickness. The splitting of coal seams is a common feature of Early Permian Gondwana coal measures of peninsular India and has been attributed to crevasse

Table 1. Gondwana stratigraphy of East Bokaro sub-basin, Jharkhand, India.

\begin{tabular}{|c|c|c|}
\hline Age & Formation & Sedimentary characters \\
\hline Middle Permian & Barren Measures & $\begin{array}{l}\text { Brown to grey, medium to fine, lenticular channel shaped } \\
\text { sandstone bodies, overlain by red, green and carbonaceous } \\
\text { shale; the sequence occurs repeatedly in cyclical order. }\end{array}$ \\
\hline Early Permian & Barakar & $\begin{array}{l}\text { Buff, grey, coarse, medium and fine grained sandstone; } \\
\text { overlying fine clastics include shale, siltstone and coal which } \\
\text { are thick and persistent in the middle and upper parts. The } \\
\text { sandstone, shale and coal occur as fining upward cycles. }\end{array}$ \\
\hline Early Permian & Karharbari & $\begin{array}{l}\text { Conglomeratic, pebbly, coarse and medium grained coalescing } \\
\text { sandstone bodies; associated fine clastics and coal beds, thin, } \\
\text { and locally thick and persistent. }\end{array}$ \\
\hline Early Permian-Late Carboniferous & Talchir & $\begin{array}{l}\text { Thin lenses of massive and stratified tillite, associated with } \\
\text { thin massive and cross-bedded green sandstone and laminated } \\
\text { green shale with or without drop stones. }\end{array}$ \\
\hline
\end{tabular}

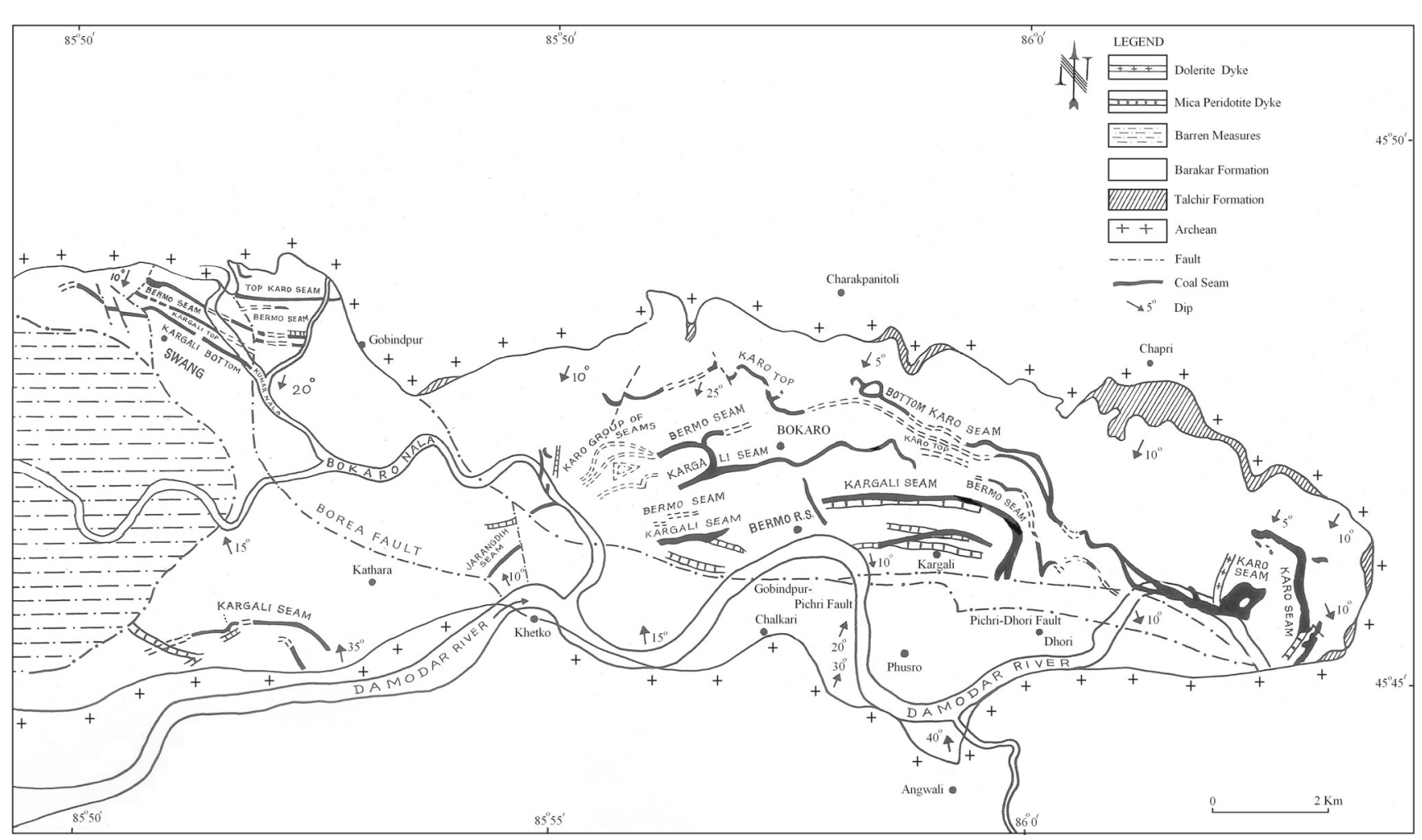

Figure 2. Geological map of East Bokaro sub-basin showing various coal seams. Seam splitting in Kargali near Phusro is noteworthy. 


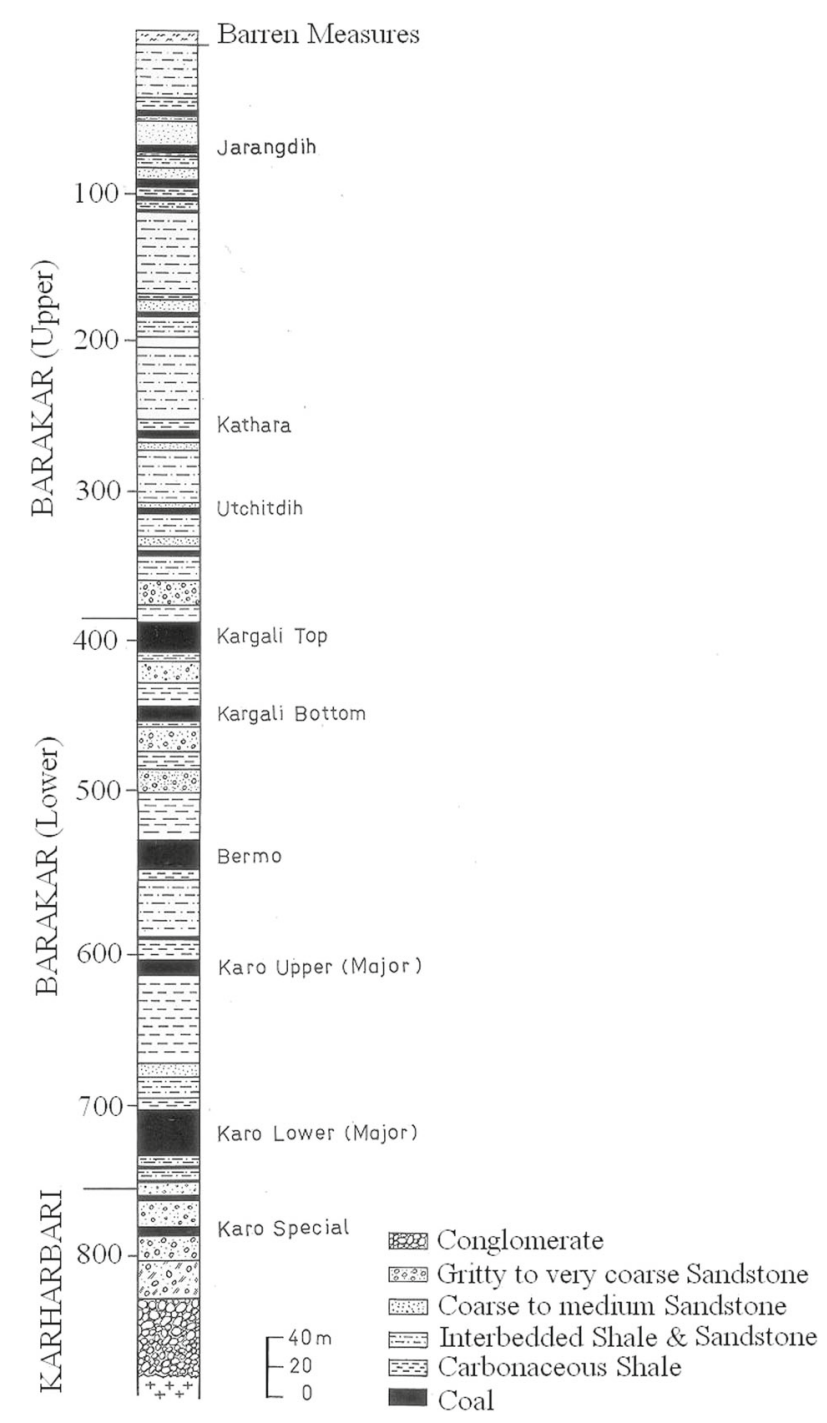

Figure 3. Stratigraphic section of early Permian Barakar Formation of East Bokaro sub-basin showing vertical arrangement of coal seams.

channeling in the areas of peat accumulation (Casshyap and Tewari 1984; Tewari 1997; Khan and Tewari 2010).

\section{Basic data and analytical method}

The remarkable feature of coal seam is its banded structure. Examination of exposed coal seams in quarry sections of Kargali (top and bottom) seam indicate that the coal bed is made of interbedded successions of common macro lithotypes such as Vitrain, Clarain, Durain, and Fusain. They are recognized on the basis of distinct physical characters. Vitrain is the bright glossy and homogenous component of coal having vitreous luster and conchoidal fracture. It occurs as thin (up to $10 \mathrm{~cm}$ ) sheet-like layers showing sharp contacts with the other lithotypes. Clarain is less bright than Vitrain. It is heterogeneous material with a banded structure and characterized by definite and smooth surface when fractured at right angles to the bedding plane. It is likewise thin (up to $15 \mathrm{~cm}$ ) having sharp contacts with other lithotypes. Occasionally, it shows lens-like geometry and die out along the strike. Durain is the greyish black hard component of coal. It is heterogeneous and shows granular texture. The Fusain occurs as patches or wedges of soft fibrous material resembling charcoal. It is highly friable and can be readily powdered by fingers. These megascopically distinguishable constituents of coal referred to as 'coal lithotypes' are taken as four distinct states as: (1) Vitrain, (2) Clarain, (3) Durain, and (4) Fusain. The basic data comprises vertical transition from one to another macro lithotype (state). A total of 820 such vertical transition data were collected separately from Kargali Top (574) and Kargali Bottom (246) seam from quarry sections of Kargali colliery of East Bokaro sub-basin.

\subsection{Markov chain model ( $M C M$ )}

A Markov chain is a probabilistic model that exhibits a special type of dependence. An excellent introduction to Markov chain process from mathematical stand point has been given in Schwarzacher (1975) and Davis (2002). The model explains that if a state at time $t_{0}$ is known, the conditional distribution of state after time $t_{0}$ is related to state before time $t_{0}$. It means that given the present, the future does depend on the past. This property is called Markov property.

The Markov chain model uses transition probability matrix between different states of variables to predict future states on stochastic processes. Moreover, the model can incorporate geological knowledge much more easily than other geostatistical models, so its results can be close to true subsurface characterization. Many papers use MCM to simulate strata and make a great progress in some content. Following the pioneer work of Vistelius (1949), numerous stratigraphic applications have been published including those of Krumbein and Dacey (1969); Gingerich (1969); Miall (1973); Carr (1982); Casshyap and Khan (1982); Hota and Maejima (2004); Tewari et al. (2009). For the most part, these studies were concerned with attempts to isolate systematic transition patterns that could then be interpreted in terms of sedimentological processes or cyclic phenomenon.

Markov chain can be expressed by a simple transition matrix in one dimension; the elements of 
matrix correspond to transition probabilities using $\mathrm{n}$ different states.

$P=\begin{array}{ccc}\text { state } 1 & \text { state } 2 & \text { state } n \\ p_{11} & p_{12} & p_{1 n} \\ p_{21} & p_{22} & p_{2 n} \\ p_{31} & p_{32} & p_{3 n} \\ p_{n 1} & p_{n 2} & p_{n n}\end{array}$

Each element is more than or equal to zero, the sum of elements of each row is equal to 1.

The computational procedure for evaluating finite Markovian process is outlined by Gingerich (1969) and Casshyap and Khan (1982) and the same is followed in the present study. The upward transitions from one state to another state were recorded from the different coal seams of the Barakar Formation on different sections in the area. This information is pooled in transition count and structured in a $4 \times 4$ tally count matrix. Three probability matrices are then computed from the transition count data $\left(f_{i j}\right)$ :

(i) a transition probability matrix $\left(p_{i j}\right)$, which gives the actual probabilities of the given transition occurring in given succession was calculated as:

$$
p_{i j}=\frac{n_{i j}}{n_{++}}
$$

(ii) a transition probability matrix of expected values $\left(e_{i j}\right)$ was obtained, assuming a random succession of states. In such a matrix, the element that represents the probability of upward transitions from state $i$ to state $j$ is calculated simply as:

$$
e_{i j}=n_{i j} / n_{++}-n_{i+}
$$

(iii) a difference matrix $\left(d_{i j}\right)$ was obtained by subtracting the $p_{i j}$ matrix from the $e_{i j}$ matrix. It has both positive and negative entries, where positive entries $>0.1$ are interpreted as being the 'dominant' transition and indeed used to link various states in preferred vertical order.

\subsubsection{Test of significance}

Statistical tests are commonly applied to the null hypothesis of a random process to verify whether a Markov property is significant and establish the structure of the repetitive pattern. The Markovian property has been tested by chi-square statistics proposed by Billingsley (1961) that either the successive states are the result from an independent process or, if not resulting from an independent process, this could form a Markov chain. The test statistics is

$$
\chi^{2}=\sum_{i, j}^{n}\left(f_{i j}-f_{i} e_{i j}\right)^{2} / f_{i} e_{i j} .
$$

Such a test would have $(m-1)^{2}-m$ degree of freedom from an original $m \times m$ tally matrix. $f_{i j}=$ transition count matrix, $f_{i}=$ frequency distribution of states, $e_{i j}=$ independent trail matrix. Following the convention of Fisher, acceptance of the null hypothesis will be assumed at 5\% confidence level and rejection of the null hypothesis at $1 \%$ confidence level.

\subsection{Entropy analysis}

The extent and ordering of the transitions in measured sections was further analyzed by applying the concept of 'Entropy' to a finite Markov probability matrix as applied by many sedimentologists (Hattori 1976; Khan and Casshyap 1981; Hota and Maejima 2004; Khan and Tewari 2007, 2013; Tewari et al. 2009). Hattori (1976) has recognized two types of entropies, one is entropy after deposition (i.e., post-depositional) and refers to leaving a particular $j$ th state for any other state and is designated as $E_{i}^{\text {(post) }}$, while the other, which refers to entering a particular $j$ th state from any other state is entropy before deposition (i.e., pre-depositional) and is designated as $E_{i}^{\text {(pre) }}$. These two types of entropies pertain to every state; one is relevant to the Markov matrix expressing the upward transition and the other relevant to Markov matrix expressing the downward transition. The latter and the former with respect to a certain state, making entropy set, correspond to the degree of randomness in its linking with others which occur as the precursor and the successor respectively.

Entropy after deposition (i.e., across the row) with respect to state $i$ is defined by Hattori (1976) and computed from the upward probability matrix $\left(p_{i j}\right)$ as:

$$
E_{i}^{(\text {post })}=-\sum_{i=1}^{n} p_{i j} \log _{2} p_{i j} .
$$

Downward ordering of the states in the succession can be obtained by dividing each of the cell value in transition count matrix $n_{i j}$ by its respective column total as:

$$
q_{j i}=\frac{n_{i j}}{n_{+j}} .
$$

Entropy before the deposition (i.e., along the column of downward matrix) has been expressed with respect to state $i$ by Hattori (1976) as:

$$
E_{i}^{(\mathrm{pre})}=-\sum_{j=1}^{n} q_{j i} \log _{2} q_{j i} .
$$

Since the entropy values (entropy before deposition and entropy after deposition) are dependent on the number of states, it is necessary to normalize them as:

$$
\text { Normalized entropy } R=\frac{E}{E_{(\max )}}
$$


Table 2. Markov chain matrices for coal lithotypes in Kargali top seam of East Bokaro sub-basin.

\begin{tabular}{|c|c|c|c|c|}
\hline Coal lithotypes & Vitrain & Clarain & Durain & Fusain \\
\hline \multicolumn{5}{|l|}{ Tally count matrix $\left(f_{i j}\right)$} \\
\hline Vitrain & 0 & 102 & 33 & 12 \\
\hline Clarain & 71 & 0 & 84 & 20 \\
\hline Durain & 42 & 48 & 0 & 65 \\
\hline Fusain & 34 & 25 & 38 & 0 \\
\hline \multicolumn{5}{|l|}{ Transition probability matrix $\left(p_{i j}\right)$} \\
\hline Vitrain & 0 & 0.698 & 0.224 & 0.077 \\
\hline Clarain & 0.405 & 0 & 0.480 & 0.114 \\
\hline Durain & 0.272 & 0.311 & 0 & 0.422 \\
\hline Fusain & 0.350 & 0.257 & 0.392 & 0 \\
\hline \multicolumn{5}{|l|}{ Independent trails probability matrix $\left(e_{i j}\right)$} \\
\hline Vitrain & 0 & 0.409 & 0.363 & 0.227 \\
\hline Clarain & 0.368 & 0 & 0.388 & 0.243 \\
\hline Durain & 0.350 & 0.418 & 0 & 0.231 \\
\hline Fusain & 0.315 & 0.374 & 0.330 & 0 \\
\hline \multicolumn{5}{|l|}{ Difference matrix $\left(d_{i j}\right)$} \\
\hline Vitrain & 0 & +0.289 & -0.139 & -0.150 \\
\hline Clarain & +0.037 & 0 & +0.092 & -0.129 \\
\hline Durain & -0.078 & -0.107 & 0 & +0.191 \\
\hline Fusain & +0.035 & -0.117 & +0.062 & 0 \\
\hline \multicolumn{5}{|l|}{ Test of significance } \\
\hline \multicolumn{5}{|l|}{ Test equation: Billingsley (1961). } \\
\hline \multicolumn{5}{|l|}{ Computed value of $\chi^{2}: 328.01$} \\
\hline \multicolumn{5}{|l|}{ Degree of freedom: 5.} \\
\hline Limiting value of $\chi^{2}$ at $0.1 \%$ confidence level: 16.7 . & & & & \\
\hline
\end{tabular}

where $E_{(\max )}$ is $\log _{2} 1 / n-1$ and $n$ is the number of state.

$E_{i}^{\text {(pre) }}$ and $E_{i}^{\text {(post) }}$ serve as indicators of the variety of transitions immediately after and before the occurrence of state $i$, respectively. Hattori (1976) also listed interpretations for a set of relations between $E_{i}^{(\text {pre })}$ and $E_{i}^{\text {(post) }}$ including the significance of state $i$ with respect to succeeding or preceding states in a sequence, and also the influence of state $i$ on its successor $\left(E_{i}^{(\text {pre })}>E_{i}^{(\text {post })}\right)$ or dependency of its precursor $\left(E_{i}^{(\text {post })}>E_{i}^{(\text {pre })}\right)$. By plotting $E_{i}^{\text {(pre) }} v s . E_{i}^{\text {(post) }}$ for each state, one can make some interpretation to the style of cyclicity and the way in which the cycles are truncated.

\section{Results and environmental discussion}

\subsection{Markov chain analysis}

Kargali Top seam. Table 2 records the bulk tally matrix as well as calculated values of three matrices $\left(e_{i j}, p_{i j}\right.$ and $\left.d_{i j}\right)$ for the Kargali top seam of the Barakar coal measures. For each transition

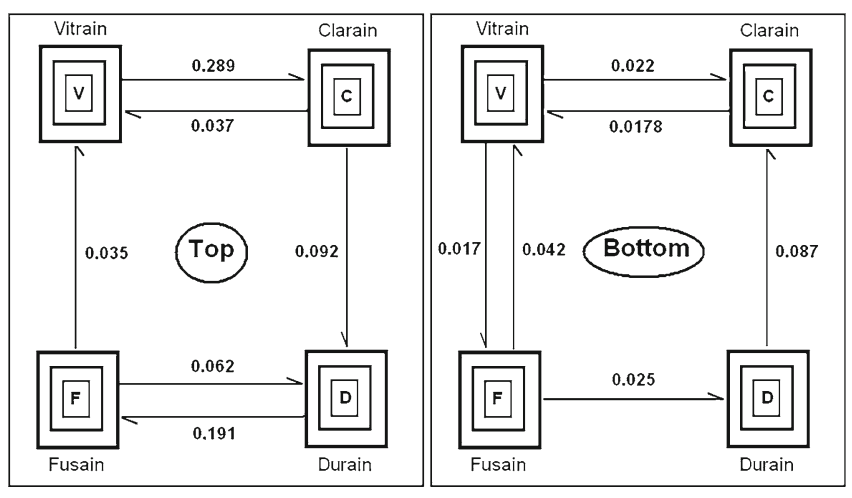

Figure 4. Markov diagrams of coal lithotypes in Kargali (top and bottom) coal seam.

couplet, the row letter represents the lower lithotype and the column letter, the upper lithotype. Chi square $\left(\chi^{2}\right)$ result is also tabulated (table 2 ), and the presence of Markovian property in this coal stratum is clearly indicated. Markov transition diagrams in figure 4 give only those vales of transition probability matrix for which corresponding 
entries in the difference matrix show positive difference. Highest values of $p_{i j}$ matrix or the positive values in $d_{i j}$ matrix link the coal lithotypes distinctly, and a strong preferred upward transition path for lithotype changes that can be derived is: Vitrain $\rightarrow$ Clarain $\rightarrow$ Durain $\leftrightarrow$ Fusain $\rightarrow$ Vitrain. A noteworthy feature with this coal seam is a twoway transition between Durain and Fusain, implying that interbedding of the two lithotypes has a greater probability of occurrence in the observed data than would be expected if the lithotypes were interbedded randomly. The coal lithotype transitions as deduced here is by and large comparable with few exceptions and closely similar to the cyclical sequences of carboniferous coal measures of Australia (Smyth 1972).

Kargali Bottom seam. The tally count matrix $\left(f_{i j}\right)$ was structured and other matrices were derived from it to test the hypothesis, whether all the coal lithotypes were deposited in a preferred order. The chi square $\left(\chi^{2}\right)$ value after Billingsley (1961) at 5 degree of freedom is significantly different at $99.5 \%$ confidence level (table 3 ) so that the hypothesis of a preferred order can safely be accepted. The computed value of $\chi^{2}$ exceeds the limiting value suggesting the presence of Markovity and cyclic arrangement of banded coal lithotypes. The Markov chain model for the Kargali bottom seam of the East Bokaro Gondwana sub-basin is based on the transition probability $\left(p_{i j}\right)$ matrix and positive values of the difference matrix $\left(d_{i j}\right)$. Figure 4 shows a simplified version of the results so obtained, the major transitions, that is transition with a probability greater than or equal to an arbitrary limit of 0.10 are shown by arrows. The transition sequence that can be derived as: Clarain $\leftrightarrow$ Vitrain $\leftrightarrow$ Fusain $\rightarrow$ Durain $\rightarrow$ Clarain.

\subsection{Entropy analysis}

The calculated values of upward transitional probability matrix $\left(p_{i j}\right)$ and downward probability matrix $\left(q_{j i}\right)$ as derived from transitional tally matrix $\left(f_{i j}\right)$ recorded in tables 2 and 3 and the entropy values of $E^{\text {(pre) }}, E^{\text {(post) }}, R^{\text {(pre) }}$ and $R^{\text {(post) }}$

Table 3. Markov chain matrices of coal lithotypes in Kargali bottom seam of East Bokaro sub-basin.

\begin{tabular}{|c|c|c|c|c|}
\hline Coal lithotypes & Vitrain & Clarain & Durain & Fusain \\
\hline \multicolumn{5}{|l|}{ Tally count matrix $\left(f_{i j}\right)$} \\
\hline Vitrain & 0 & 52 & 17 & 24 \\
\hline Clarain & 61 & 0 & 12 & 09 \\
\hline Durain & 14 & 16 & 0 & 04 \\
\hline Fusain & 18 & 14 & 05 & 0 \\
\hline \multicolumn{5}{|l|}{ Transition probability matrix $\left(p_{i j}\right)$} \\
\hline Vitrain & 0 & 0.558 & 0.182 & 0.258 \\
\hline Clarain & 0.744 & 0 & 0.146 & 0.109 \\
\hline Durain & 0.412 & 0.470 & 0 & 0.117 \\
\hline Fusain & 0.487 & 0.378 & 0.135 & 0 \\
\hline \multicolumn{5}{|l|}{ Independent trail probability matrix $\left(e_{i j}\right)$} \\
\hline Vitrain & 0 & 0.536 & 0.222 & 0.241 \\
\hline Clarain & 0.566 & 0 & 0.207 & 0.226 \\
\hline Durain & 0.438 & 0.383 & 0 & 0.175 \\
\hline Fusain & 0.445 & 0.394 & 0.160 & 0 \\
\hline \multicolumn{5}{|l|}{ Difference matrix $\left(d_{i j}\right)$} \\
\hline Vitrain & 0 & +0.022 & -0.040 & +0.017 \\
\hline Clarain & +0.178 & 0 & -0.061 & -0.017 \\
\hline Durain & -0.026 & +0.087 & 0 & -0.058 \\
\hline Fusain & +0.042 & -0.016 & +0.025 & 0 \\
\hline \multicolumn{5}{|l|}{ Test of significance } \\
\hline \multicolumn{5}{|l|}{ Test equation: Billingsley (1961). } \\
\hline \multicolumn{5}{|l|}{ Computed Value of $\chi^{2}: 103.32$} \\
\hline \multicolumn{5}{|l|}{ Degrees of freedom: 5} \\
\hline Limiting value of $\chi^{2}$ at $0.1 \%$ confidence level: 16.7 & & & & \\
\hline
\end{tabular}


obtained with the help of these matrices for individual coal lithotype are shown in tables 4 and 5 . Computed entropy values of individual lithotype are sub-equal to equal implying that the formation of these banded coal lithotypes was not a random event for the Kargali (top and bottom) coal seam of Barakar coal measures in East Bokaro sub-basin.

Out of the four coal lithotypes in the Kargali coal sequence, two namely Vitrain and Clarain in the case of Kargali top, and Fusain and Durain in the case of Kargali bottom gives $E^{\text {(pre) }}>E^{\text {(post) }}$ relationship, which indicate that lithotypes following them can be ascertained with more certainty than those preceding them. In other words, these coal types exert a strong influence on their successor while being relatively less influenced by their precursor, i.e., there is a high probability of these lithotypes passing up into Durain in case of Kargali top whereas Clarain in the case of Kargali bottom but may occur after different lithotypes, as was recognized in the colliery section of the area of study. In environmental term, this relation indicates that anaerobic conditions with varying degree of exposure to atmospheric oxygen in earlier stage of formation developed widely and repeatedly during the formation of Kargali top coal seam, whereas, in Kargali bottom coal seam the aerobic conditions developed below water table and the peat deposit swept by forest fires that generated intense heat and/or subsurface oxidation of coal, controlled, to a great extent, the sequence of coal lithotypes in the fluvial system of the Barakar coal measures. This fact is also evident in the area, as the Clarain and Vitrain show maximum representation as compared to other lithotypes. By contrast, the remaining coal lithotypes have $E^{\text {(pre) }}<E^{\text {(post) }}$ indicating that formation of each of these lithotypes was strongly influenced by the preceding lithotypes. This relationship supports in a statistical way, the otherwise geologically obvious conclusion that the formation of these coal types depends largely on specific area of fluvial environment. The inference deduced from entropy analysis compares well with the conclusion derived independently from embedded Markov chain model discussed earlier.

The two entropies for each coal lithotype $E^{(\text {pre })}$ and $E^{\text {(post) }}$, as described above, yield 'entropy set' (Hattori 1976). Hattori (1976) plotted entropy sets for strata of different environment and recognized six shapes according to the respective type of cyclical sedimentation and classed them as Type A-1,

Table 4. Markov matrices equated to entropies for the individual coal lithotypes in Kargali bottom seam, East Bokaro sub-basin.

\begin{tabular}{|c|c|c|c|c|c|}
\hline Coal lithotypes & Vitrain & Clarain & Durain & Fusain & \\
\hline \multicolumn{6}{|c|}{ Tally count matrix $\left(f_{i j}\right)$} \\
\hline Vitrain & 0 & 52 & 17 & 24 & \\
\hline Clarain & 61 & 0 & 12 & 09 & \\
\hline Durain & 14 & 16 & 0 & 04 & \\
\hline Fusain & 18 & 14 & 05 & 0 & \\
\hline \multicolumn{6}{|c|}{ Transition probability matrix $\left(p_{i j}\right)$} \\
\hline Vitrain & 0 & 0.558 & 0.182 & 0.258 & \\
\hline Clarain & 0.744 & 0 & 0.146 & 0.109 & \\
\hline Durain & 0.412 & 0.470 & 0 & 0.117 & \\
\hline Fusain & 0.487 & 0.378 & 0.135 & 0 & \\
\hline \multicolumn{6}{|c|}{ Downward probability matrix $\left(q_{i j}\right)$} \\
\hline Vitrain & 0 & 0.634 & 0.500 & 0.650 & \\
\hline Clarain & 0.656 & 0 & 0.353 & 0.243 & \\
\hline Durain & 0.150 & 0.195 & 0 & 0.106 & \\
\hline Fusain & 0.193 & 0.170 & 0.147 & 0 & \\
\hline \multicolumn{6}{|c|}{ Calculated value of entropy set of coal lithotypes } \\
\hline Coal lithotypes & $E^{\text {(pre) }}$ & $E^{\text {(post) }}$ & $R^{\text {(pre) }}$ & $R^{\text {(post) }}$ & Relationship \\
\hline Vitrain & 1.315 & 1.407 & 0.829 & 0.887 & $E^{\text {(pre })}<E^{\text {(post) }}$ \\
\hline Clarain & 1.418 & 1.040 & 0.894 & 0.656 & $\left.E^{(\text {pre }}\right)<E^{(\text {post })}$ \\
\hline Durain & 1.208 & 1.378 & 0.762 & 0.870 & $E^{(\text {pre })}>E^{(\text {post })}$ \\
\hline Fusain & 1.295 & 1.418 & 0.817 & 0.894 & $E^{(\text {pre })}>E^{(\text {post })}$ \\
\hline
\end{tabular}

$E^{(\text {pre })}=$ Entropy before deposition. $R^{(\text {pre })}=$ Normalized entropy before deposition.

$E^{\text {(post) }}=$ Entropy after deposition. $R^{\text {(post) }}=$ Normalized entropy after deposition. 
Table 5. Markov matrices equated to entropies for the individual coal lithotypes in Kargali top seam, East Bokaro sub-basin.

\begin{tabular}{|c|c|c|c|c|c|}
\hline Coal lithotypes & Vitrain & Clarain & Durain & Fusain & \\
\hline \multicolumn{6}{|c|}{ Tally count matrix $\left(f_{i j}\right)$} \\
\hline Vitrain & 0 & 102 & 33 & 12 & \\
\hline Clarain & 71 & 0 & 84 & 20 & \\
\hline Durain & 42 & 48 & 0 & 65 & \\
\hline Fusain & 34 & 25 & 38 & 0 & \\
\hline \multicolumn{6}{|c|}{ Transition probability matrix $\left(p_{i j}\right)$} \\
\hline Vitrain & 0 & 0.698 & 0.224 & 0.258 & \\
\hline Clarain & 0.405 & 0 & 0.480 & 0.109 & \\
\hline Durain & 0.272 & 0.311 & 0 & 0.117 & \\
\hline Fusain & 0.350 & 0.257 & 0.392 & 0 & \\
\hline \multicolumn{6}{|c|}{ Downward probability matrix $\left(q_{i j}\right)$} \\
\hline Vitrain & 0 & 0.582 & 0.212 & 0.124 & \\
\hline Clarain & 0.483 & 0 & 0.542 & 0.206 & \\
\hline Durain & 0.285 & 0.274 & 0 & 0.670 & \\
\hline Fusain & 0.231 & 0.143 & 0.245 & 0 & \\
\hline \multicolumn{6}{|c|}{ Calculated value of entropy set of coal lithotypes } \\
\hline Coal lithotypes & $E^{\text {(pre) }}$ & $E^{\text {(post) }}$ & $R^{\text {(pre) }}$ & $R^{\text {(post) }}$ & Relationship \\
\hline Vitrain & 1.278 & 1.084 & 0.806 & 0.684 & $E^{\text {(pre) }}<E^{\text {(post) }}$ \\
\hline Clarain & 1.451 & 1.397 & 0.952 & 0.880 & $E^{(\text {pre })}<E^{(\text {post })}$ \\
\hline Durain & 1.404 & 1.553 & 0.886 & 0.980 & $E^{(\text {pre })}>E^{(\text {post })}$ \\
\hline Fusain & 1.377 & 1.557 & 0.868 & 0.982 & $E^{(\text {pre })}>E^{(\text {post })}$ \\
\hline
\end{tabular}

A-2, A-3, A-4, B, and C. The same method was used here to discriminate the cyclical pattern.

The plot of the $E^{\text {(pre) }}$ and $E^{\text {(post) }}$ values for each coal lithotypes are graphically plotted in figure 5 . The figure shows that entropy sets for all lithotypes of Kargali top and bottom coal seams are located within the limiting range, A-4 cyclic pattern. Of Hattori's diagram, this one most closely (though not exactly) follows that expected from an asymmetrical cyclic sequence. The asymmetrical cyclic sequences are similar to those that have been described in Australian coal (Smyth 1972; Shibaoka and Smyth 1975; Scott 2002).

\subsection{Environmental interpretation}

The Early Permian Gondwana coal measures of peninsular India are fluvial deposits that accumulated in river valleys (Casshyap 1979; Casshyap and Tewari 1984; Tewari 2005). The vegetal matter therefore forming the bulk of Permian Gondwana coal was likewise deposited under freshwater conditions. The resultant coal seams are characterized by abundant dirt bands and show frequent splitting by channel-like sandstone bodies. Recent geostatistical studies of subsurface logs from many

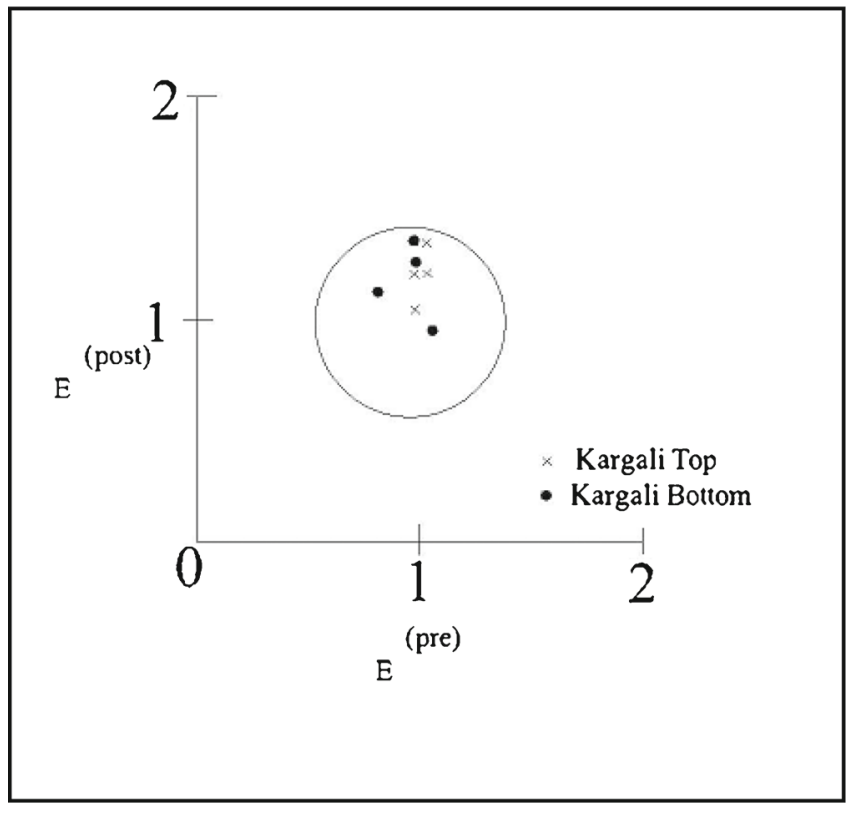

Figure 5. Entropy set for coal lithotypes of early Permian Barakar Formation of East Bokaro sub-basin.

Gondwana sub-basins of eastern and central India using Markov chain, entropy, cluster analysis, factor 
analysis, and principal component analysis have given new insights for the development of coal swamps in fluvial settings (Khan and Tewari 2013). It is visualized that the early Permian Barakar coals are formed in abandoned channels, interchannel areas, distal levees, and flood plains. The preferred orientation of plant fossils and their definite relationship with the Permian paleoslopes in many coalfields of eastern and central India in as much as high percentage of dirt contents are features suggestive of transport of vegetal debris in the flood plains of Permian rivers to form peat bog (Tewari 1998). Most of the Permian Gondwana coals are, therefore, of allochthonous (drifted) nature unlike the carboniferous European and Australian autochthonous (in situ) coals. However, locally from one quarry section in Saharjuri coalfield of Jharkhand, the in situ plant growth is reported (Niyogi 1966; Banerjee 2005).

It is evident from the results of Markov chain model and entropy analysis that the formation of various coal lithotypes is not a random event and they follow definite vertical order. The occurrence of coal lithotypes in the Kargali seam is therefore not random and follows the cyclic repetition of Vitrain, Clarain, Durain, and Fusain. Indeed, there is no definite criteria where to begin a cycle in coal lithotype sequences. However, in the coal bearing sedimentary successions, sandstone represents the base and coal as top of the cycles (Duff and Walton 1962).It is here proposed that the highest linkage in the difference matrix of MCM should represent the base of the cycle. Each coal lithotype cycle of Kargali seam should therefore begin with Vitrain and end up to Fusain, the Vitrain shows highest linkage in both the bottom and top seams in Markov chain model (figure 4). The preferred upward transition of coal lithotypes in Kargali bottom and Kargali top seams of East Bokaro sub-basin is by and large similar as follows:

\section{Kargali Top \\ Vitrain $\rightarrow$ Clarain $\rightarrow$ Durain $\leftrightarrow$ Fusain $\rightarrow$ Clarain Kargali Bottom}

Clarain $\leftrightarrow$ Vitrain $\leftrightarrow$ Fusain $\rightarrow$ Durain $\rightarrow$ Clarain

Commonly, the Barakar coals are dominantly made up of variable amount of Durain and Vitrain. The other lithotypes of Clarain and Fusain are less common, though the latter occurs as irregular patches. However, some coal beds occurring in the lower part of Barakar, Vitrain, Clarain, and Durain share sub-equal amount whereas Fusain shows irregular distribution (Sen 1999). The Kargali seam of East Bokaro sub-basin occurs in the lower part of the succession and exhibits the above characteristics. Coal petrographic studies (Sen 1999) have shown vitrinite (53-55\%) and inertinite (45-47\%) as dominant macerals in the Barakar coal.

The coal is believed to have formed by a sequence of natural geochemical and bio-geochemical processes from the accumulated and buried plant remains. It is widely accepted that cellulose, lignin and hydrogen rich waxy resinous ingredients organic compounds contribute to coal seam formation (Stach et al. 1982). In addition, the toxicity of the basin floor where peat is formed as well as the subsurface water table also control the decomposition of vegetal matter into biochemical stage. The high toxic environment favours least decomposition of vegetal matter and lead to form Vitrain, whereas in less toxic condition cellulose is destroyed and the hemi-cellulose and lignin together form Clarain (Teichmuller and Teichmuller 1982). Similarly, a high ground water level together with specific toxic environment favours Vitrain, whereas during low water level, the oxidization prevails and Durain is formed.

The Vitrain layer of the Kargali seam suggests high toxic conditions and relatively higher water table in the protected flood plain areas of Permian rivers. A gradual decline in the toxicity of the medium and the water level as well may have terminated the formation of Vitrain and favoured the development of Clarain. The close interbedding of Vitrain and Clarain definitely indicates rapid seasonal fluctuations with wet-reducing (anaerobic) to dry-oxidative (aerobic) conditions through time during peat formation. The preferred upward transition of Clarain to Durain and Durain to Fusain further indicate reduction in toxic medium and lowering of water table.

\section{Conclusions}

The embedded Markov chain was applied in this study to detect the presence of cyclicity in the banded structures of Kargali coal seam of East Bokaro Gondwana sub-basin. Results suggest that the banded coal subsequences can be represented by the most preferred path of upward coal lithotype transitions as follows: Clarain $\leftrightarrow$ Vitrain $\leftrightarrow$ Fusain $\rightarrow$ Durain $\rightarrow$ Clarain (for Kargali bottom) and Vitrain $\rightarrow$ Clarain $\rightarrow$ Durain $\leftrightarrow$ Fusain $\rightarrow$ Vitrain (for Kargali top).

Reversible and subsidiary transitions may occur between some banded coal structures. The interbedding between Vitrain and Clarain, and Fusain and Durain in Kargali coal seam is suggestive of seasonal fluctuation in anaerobic and aerobic conditions during peat formation. In general, this order of preferred transitions is closely comparable with that suggested for the carboniferous coal measures of Australia and Europe. 
Entropy results also corroborate the conclusions deduced independently from embedded Markov chain by plotting $E^{\text {(pre) }}$ against $E^{\text {(post) }}$ which signifies asymmetrical cycle of Type A-4. Environmentally it is visualized that a gradual decline in toxic environment and ground water level conditions resulted in the banded coal lithotypes in the Kargali coal seam of East Bokaro sub-basin.

\section{Acknowledgements}

The authors thank the collieries administration of Bermo and Kargali collieries of East Bokaro subbasin for hospitality during collection of data. They also appreciate useful suggestions by the reviewers of the Journal of Earth System Science.

\section{References}

Banerjee M 2005 Autochthonous deposition of Indian coal beds with palaebotanical evidences of in situ plants from Saharjuri basin, Jharkhand; Curr. Sci. 88(9) 1487-1490.

Billingsley P 1961 Statistical methods in chains; Ann. Math. Statist. 32 12-40.

Carr T R 1982 Log-linear models, Markov chain and cyclic sedimentation; J. Sedim. Petrol. 52 905-912.

Casshyap S M 1979 Pattern of sedimentation in Gondwana basins; 4 th International Gondwana Symposium, Calcutta 2 525-551.

Casshyap S M and Khan Z A 1982 Discrete Markov analysis of Permian coal measures East Bokaro basin, Bihar, India; Indian J. Earth Sci. 9 99-107.

Casshyap S M and Tewari R C 1984 Fluvial models of the Lower Permian Gondwana coal measures of SonMahanadi and Koel-Damodar basins, India; In: Coal and Coal bearing sequences (eds) Rahmani R A and Flores R M, Spec. Publ. Inter. Assoc. Sedimentologists 7 121-147.

Casshyap S M and Tewari R C 1988 Depositional models and tectonic evolution of Gondwana basins; The Paleobotanist 36 59-66.

Casshyap S M, Tewari R C and Khan Z A 1988 Interrelationship of stratigraphic and lithological variables in Permian fluviatile Gondwana coal measure of eastern India; Proc. Symp. Quantitative Stratigraphic Correlation, IIT Kharagpur, pp. 111-125.

Davis J C 2002 Statistics and Data Analysis in Geology; 3rd edn, John Wiley \& Sons, New York.

Duff P, Mc L D and Walton E K 1962 Statistical basis for cyclothems: A quantitative study of the sedimentary succession in the East Pennine coalfield; Sedimentology 1 235-256.

Gingerich P D 1969 Markov analysis of cyclic alluvial sediments; J. Sedim. Petrol. 39 330-332.

Hattori I 1976 Entropy in Markov chain and discrimination of cyclic patterns in lithologic succession; J. Math. Geol. 8 477-497.

Hota R N and Maejima W 2004 Comparative study of cyclicity of lithofacies in lower Gondwana Formations of Talchir basin: A statistical analysis of subsurface logs; Gondwana Res. 7 353-362.

Khan Z A and Casshyap S M 1981 Entropy in Markov chain analysis of Late Paleozoic cyclical coal measures of East Bokaro basin, Bihar; Math. Geol. 13 153-162.
Khan Z A and Casshyap S M 1982 Sedimentological synthesis of Permian fluviatile sediments of East Bokaro basin; Sedim. Geol. 33 111-128.

Khan Z A and Tewari R C 2007 Quantitative model of Early Permian coal bearing Barakar cycles from SonMahanadi and Koel-Damodar Gondwana coalfields of eastern-central India; Gondwana Geol. Mag. 9 115-125.

Khan Z A and Tewari R C 2010 Multivariate analysis of coal bearing Barakar cyclothems (Late Paleozoic) in Singrauli sub-basin, central India; Gondwana Geol. Mag. 12 133140.

Khan Z A and Tewari R C 2011 R-mode factor analysis of lithological variables from cyclically deposited Late Paleozoic Barakar sediments in Singrauli Gondwana subbasin, peninsular India; J. Asian Earth Sci. 12 133-140.

Khan Z A and Tewari R C 2012 Principal component analysis of lithological variables in Early Permian Barakar coal measures, western Singrauli Gondawana sub-basin of central India; J. Geol. Soc. India 79 404-410.

Khan Z A and Tewari R C 2013 Geostatistical analysis of the Barakar cyclothems (Early Permian): A case study from the subsurface logs in Singrauli Gondwana sub-basin of central India; Int. J. Geol. Earth Environ. Sci. 3 41-62.

Krumbein W C and Dacey M F 1969 Markov chain and embedded Markov chain in geology; Math. Geol. 1 79-96.

Niyogi D 1966 Lower Gondwana sedimentation in Saharjuri coalfield, Bihar, India; J. Sedim. Petrol. 36 960-972.

Miall A D 1973 Markov chain analysis applied to an ancient fluvial plain succession; Sedimentology 20 347-364.

Mishra H K, Chandra T K and Verma R P 1990 Petrology of some Permian coals of India; Int. J. Coal Geol. 16 47-71.

Schwarzacher W 1975 Sedimentation Models and Quantitative Stratigraphy; Elsevier Publ. Co., New York, 396p.

Scott A C 2002 Coal petrology and the origin of coal macerals: A way ahead; Int. J. Coal Petrol. 50 119-134.

Sen S 1999 A new model of coal seam formation vis-a-vis banded structure; Energy Sources 21(7) 573-580.

Sen S 2010 Indian Bituminous Coals from the Lower Gondwana Basins and Tertiart deposits: An appraisal; Gondwana Geol. Mag. 12 161-164.

Shibaoka M and Smyth M 1975 Coal petrology and the formation of coal seams in some Australian sedimentary basin; Econ. Geol. 70 1463-1473.

Singh R M and Dwivedi C S 1994 A study of coal facies in the Korba sub-basin, Mahanadi valley, India; Int. J. Coal Geol. 25 113-132.

Singh M P and Shukla R R 2004 Petrographic characteristics and depositional conditions of Permian coals of Pench, Kanhan and Tawa valley coalfields of Satpura basin, Madhya Pradesh, India; Int. J. Coal Geol. 59 209-243.

Singh B D and Singh A 2004 Observations on Indian Permian Gondwana coals under fluorescence microscopy; Gondwana Res. 7 143-151.

Singh P K, Singh M P, Prachiti P K, Kalpana M S, Manikyamba C, Lakshminarayan G, Singh A K and Naik A S 2012 Petrographic characteristic and carbon isotopic composition of Permian coal: Implications on depositional environment of Sattupalli coalfield, Godavari valley, India; Int. J. Coal Geol. 90-91 34-42.

Smyth M 1972 A petrographic study of the stratigraphy of Australian coal seams; Master of Science degree, Universty of Wollongong (unpublished), 81p.

Stach E, Nackowsky M T, Teichmuller M, Taylor G H, Chandra D and Teichmuller R 1982 Stach's Textbook of Coal Petrology; 3rd edn, Gebruder Borntraeger, Berlin.

Teichmuller M and Teichmuller R 1982 The geological basis of coal formation; In: Stach's Textbook of Coal Petrology (eds) Stach E, Nackowsky M T, Teichmuller M, Taylor G H, Chandra D and Teichmuller R, Gebruder Borntraeger, Berlin, pp. 5-86. 
Tewari R C 1997 Numerical classification of coal bearing cycles of Early Permian Barakar coal measures of eastern-central India Gondwana basins using Q mode cluster analysis; J. Geol. Soc. India 50 593599.

Tewari R C 1998 Plant fossil orientation in early Permian Barakar Formation of eastern-central India Gondwana basins; The Paleobotanist 47 32-36.

Tewari R C 2005 Tectono-stratigraphic sedimentary events in Gondwana succession of peninsular India; J. Geol. Soc. India 65 636-638.

Tewari R C 2008 Net subsidence and evolution of coal swamps in Early Permian coal measures of eastern India Gondwana basins using principal component analysis; J. Geosci. 51 21-26.
Tewari R C and Maejima W 2010 Origin of Gondwana basins of peninsular India; J. Geosci. 53 43-49.

Tewari R C, Singh D P and Khan Z A 2009 Application of Markov chain and entropy analysis to lithologic succession - an example from Bellampali coalfield, Andhra Pradesh; India; J. Earth Sci. Syst. 118 583-596.

Tewari R C, Hota R N and Maejima W 2012 Fluvial architecture of Early Permian Barakar rocks of Korba Gondwana basin, eastern-central India; J. Asian Earth Sci. 52 43-52.

Veevers J J and Tewari R C 1995 Gondwana master basins of peninsular India between Tethys and the Gondwanaland province of Pangea; Bull. Geol. Soc. Am. 187 1-72.

Vistelius A B 1949 The mechanism of formation of sedimentary beds; Dokl. Akad. Nauk SSSR 65 191-194. 